\title{
Patient Understanding of the Neuropsychiatric Risks Associated with Branded Bupropion Hydrochloride Products Used for Smoking Cessation
}

\author{
John Ascher ${ }^{1} \cdot$ Annette Stemhagen $^{2} \cdot$ Monika Stender $^{3} \cdot$ Beta Win $^{4} \cdot$ Christina Winter $^{4}$
}

Published online: 13 August 2018

(c) The Author(s) 2018

\begin{abstract}
Background Bupropion hydrochloride (Zyban) is an effective aid to smoking cessation; however, its use has previously been associated with neuropsychiatric adverse events. Here we report results of the patient Knowledge, Attitudes, and Behavior survey that forms part of the Year 7 Risk Evaluation and Mitigation Strategy (REMS) assessment for Zyban.

Objective Assess participants' understanding of the neuropsychiatric risks associated with branded bupropion hydrochloride products that are used for smoking cessation, as described in the Medication Guides.

Methods A cross-sectional study was conducted among patients $\geq 18$ years of age, who had used or filled a prescription for branded bupropion hydrochloride for smoking cessation in the past 6 months. Participants were recruited through an online panel, pharmacy network, or by healthcare provider referral, and invited to complete a survey containing questions regarding the risks associated with the use of branded bupropion hydrochloride products, and whether they had received and read the Medication Guide. The study aimed for $\geq 80 \%$ of participants to respond correctly to each question regarding neuropsychiatric risks.

Results From the 50,985 survey invitations distributed, 1017 participants responded, of whom 144 were eligible and 142 completed the survey. Over $80 \%$ of participants correctly responded to most neuropsychiatric risk questions. Approximately three-quarters of participants received the Medication Guide when they last filled their prescription, of whom over half read the Medication Guide at that time.

Conclusions Participants enrolled in this Year 7 REMS survey had good understanding of the neuropsychiatric risks associated with using branded bupropion hydrochloride products for smoking cessation.
\end{abstract}

Electronic supplementary material The online version of this article (https://doi.org/10.1007/s40801-018-0140-2) contains supplementary material, which is available to authorized users.

Monika Stender- Real World Evidence and Epidemiology, GSK, Stockley Park, Uxbridge, Middlesex, UK (at the time of the study).

John Ascher

john.a.ascher@gsk.com

1 Classic and Established Medicines, US Medical Affairs, GSK, Research Triangle Park, NC, USA

2 Safety, Epidemiology and Risk Management, UBC, Blue Bell, PA, USA

3 Real World Evidence and Epidemiology, GSK, Stockley Park, Uxbridge, Middlesex, UK

4 Global Clinical Safety and Pharmacovigilance, GSK, Stockley Park, Uxbridge, Middlesex, UK

\section{Key Points}

As part of the Year 7 Risk Evaluation and Mitigation Strategy assessment for Zyban, we used a Knowledge, Attitudes, and Behavior survey to assess patients' knowledge of the potential neuropsychiatric risks associated with branded bupropion hydrochloride products used for smoking cessation.

Over $80 \%$ of participants correctly responded to most questions regarding neuropsychiatric risks, demonstrating a good knowledge of potential neuropsychiatric adverse events and how best to prevent them.

The Medication Guide was received by $73.9 \%$ of patients when they last filled their prescription, and the majority $(108 / 142,76.1 \%)$ of participants reported that they had read the Medication Guide in the past. 


\section{Introduction}

Bupropion hydrochloride is an antidepressant of the aminoketone class, indicated for use in smoking cessation (Zyban) [1], major depressive disorder [Wellbutrin, Wellbutrin sustained-release (SR) and Wellbutrin extendedrelease (XL)] [2-4], and seasonal affective disorder (Wellbutrin XL) [4].

The efficacy of bupropion hydrochloride in aiding smoking cessation has been demonstrated in numerous randomized controlled trials [5, 6], and recently a clinical trial and observational study have both concluded that the risk of neuropsychiatric events is not significantly increased with the use of bupropion hydrochloride for smoking cessation, as compared with placebo [7] or nicotine replacement therapy [8]. However, historic spontaneous reports to medical authorities regarding neuropsychiatric adverse events, including seizures, depression, and suicidal ideation and behavior, raised safety concerns over the use of bupropion hydrochloride for smoking cessation [9-11]. The inconsistency between these findings may be due to the different nature and source of the reports. Clinical trial reports are documented by healthcare professionals in a controlled setting, whereas spontaneous reports are by nature poorly documented, include hearsay and consumer reports, and are often missing information that is required to assess the causal relationship with the medication. Furthermore, patients recruited for clinical trials generally represent a subset of the patient population using the product in clinical practice due to the strict eligibility criteria inherent in clinical trial protocols.

The US Food and Drug Administration (FDA) uses Risk Evaluation and Mitigation Strategies (REMS) to help manage potential adverse events associated with the use of certain medications. REMS can employ a number of methods to ensure the safe use of a product, including Communication Plans, Elements to Assure Safe Use, Implementation Systems, and Medication Guides [12]. All REMS also require a Timetable for Submission of Assessments [13].

The REMS for Zyban was approved on 26 February 2010 with the goal of informing patients of the serious risks associated with the use of bupropion hydrochloride. It comprised a Medication Guide and a Timetable for Submission of Assessments at 18 months, 3 years, and 7 years after REMS approval [14]. The REMS was modified on 27 March 2014, prior to the Year 7 assessment; its revised goal was to inform patients about the potential serious risk of neuropsychiatric adverse events associated with the use of Zyban [15]. Here we report results of a patient survey that was part of the Year 7 REMS assessment.

The primary objective of the survey was to assess participants' understanding of the potential risk of neuropsychiatric adverse events associated with the use of branded bupropion hydrochloride products for smoking cessation, as described in the Medication Guides available at the time of prescription (current versions) [16-19]. The Medication Guide is a means to educate patients on the use of their branded bupropion product and any associated risks. As such, this study also assessed participants' knowledge of additional risks associated with the use of bupropion products for smoking cessation, and participants' receipt and reading of the Medication Guide. Although the REMS assessment is only required to report on patients using Zyban for smoking cessation, we also included patients using Wellbutrin, Wellbutrin SR, and Wellbutrin XL for smoking cessation in this survey, to capture any off-label use of these products.

\section{Methods}

\subsection{Study Design}

In this cross-sectional study (GSK ID 205913) we conducted a Knowledge, Attitudes, and Behavior survey among participants who were using or who had filled a prescription for a branded bupropion hydrochloride product (defined as Zyban or Wellbutrin, Wellbutrin SR, and Wellbutrin XL) for smoking cessation in the 6 months prior to survey administration. Participants were recruited between 7 October and 28 December 2016, using three different approaches: an online web panel, healthcare provider (HCP) referral, and a pharmacy network.

Participant recruitment through the online web panel was achieved through partnership with a market research company. All consumers listed within the company's proprietary database who had opted to participate in research programs, who self-identified as users of a branded bupropion hydrochloride product (within the last 6 months), and who were currently undergoing smoking cessation treatment, were invited to participate via email in the study. HCPs known to prescribe branded bupropion hydrochloride products were identified in two ways: (1) from a list of known prescribers provided by GlaxoSmithKline (GSK), and (2) by a market research company who identified prescribers of branded bupropion hydrochloride products in their database. The HCPs were asked to distribute survey invitation letters to ten patients for whom they had prescribed a branded bupropion hydrochloride product for smoking cessation, without a pre-specified sampling framework. Participants were also recruited through a pharmacy network, which identified all patients who had filled a branded bupropion hydrochloride prescription in the last 6 months; survey invitation letters were distributed accordingly.

All participants invited to take part in the survey received an invitation letter containing a unique ID code for accessing 
the survey and a copy of bupropion hydrochloride product photographs. The survey could be taken online through a secure website or by telephone with a trained Survey Coordinating Center Associate (CCA) using a Computer Assisted Telephone Interviewing program. The same survey was used regardless of how it was administered.

The survey commenced with 13 screening questions designed to eliminate ineligible respondents, collect information on participants' demographic characteristics, and classify participants by treatment formulation. Following the initial screening questions, there were 14 numbered sections comprising 40 individual questions, which assessed participants' knowledge of risks associated with the use of branded bupropion hydrochloride products, as well as information on participants' receipt and reading of the Medication Guide, and where participants usually received their branded bupropion products. All 14 numbered sections and individual questions, as they appeared in the survey, are provided in the Online Supplementary Materials. Of the 40 individual questions, 16 specifically assessed participants' knowledge of neuropsychiatric risks associated with branded bupropion hydrochloride products used for smoking cessation. Last, participants were asked if they would like to report a product complaint or any suspected adverse event experienced while taking their branded bupropion product. If participants answered yes, they were presented with a free text field in which they could report the complaint or event. Survey questions were all multiple choice and participants were required to answer all questions presented to them in order to complete the survey. It is possible that not all questions were presented to all participants due to skip logic.

All data collected during the survey were held confidentially by the sponsor and UBC and used only for the purposes stated in the survey instructions. The Electronic Data Capture (EDC) System used for data collection was compliant with 21 Code of Federal Regulations Part 11 and the Health Insurance Portability and Accountability Act. The EDC encrypted all patient-identifying data, and all such data were stored separately from survey data. All participants provided written consent to take part in the survey.

\subsection{Participants}

To be included in the study participants had to be using or to have filled a prescription for a branded bupropion hydrochloride product for smoking cessation in the 6 months prior to survey administration, be $\geq 18$ years of age, speak fluent English (for the telephone survey only), and to have consented to participate in the survey. Branded bupropion hydrochloride product use was confirmed through a series of questions concerning manufacturer information detailed on the medication container and a review of photographs of generic and branded bupropion hydrochloride products.
Any participants who were using generic bupropion hydrochloride products, who had used or filled a prescription for a branded bupropion hydrochloride product for depression alone, or who had previously participated in a branded bupropion hydrochloride survey (determined via self-report in the survey) were excluded from the study population.

\subsection{Outcomes and Assessments}

The primary outcome was the proportion of participants who correctly responded to each of the 16 individual questions concerning the neuropsychiatric risks associated with branded bupropion hydrochloride products. These risks reflect those described in the Medication Guides [16-19].

Additional outcomes included the proportion of participants who correctly responded to individual questions concerning other risks associated with the use of branded bupropion hydrochloride products. Information regarding receipt and use of the Medication Guide was also collected. This included questions on whether the Medication Guide was received with the last prescription, when the Medication Guide was last read, and how thoroughly it was read. The source from which the participant received information on the branded bupropion product and how long participants took to complete the survey were also collected.

Safety outcomes were not assessed in this survey; however, all free-text fields of the survey and telephone conversations with the CCA were monitored for reports of safety events, product quality complaints, or medical information requests. These were forwarded to GSK in accordance with the Safety Event Reporting Procedure established for this study.

\subsection{Sample Size and Statistical Analysis}

The study aimed to recruit 125 participants. Correct responses from $\geq 80 \%$ of participants to each of the 16 individual questions about the neuropsychiatric risks associated with the use of branded bupropion hydrochloride products was considered indicative of a good level of understanding of the risks stated in the Medication Guide. This threshold has been considered to reflect a good understanding of risks in previous REMS surveys of branded bupropion hydrochloride products and in surveys on other medicines [20,21].

The Completed Survey population (defined as all participants with completed surveys) was used as the primary analysis population. Statistical analyses were all descriptive. Responses to all questions were summarized by counts and percentages. Unless otherwise stated, all percentages are based on the number of participants to whom a specific question was presented. Exact binomial two-sided 95\% confidence intervals were calculated for the proportion of respondents who gave correct responses to each question 
regarding neuropsychiatric and additional risks associated with the use of branded bupropion hydrochloride products [22].

Analysis by subgroups was also performed for all risk questions. Subgroups were formed according to the following criteria: treatment formulation Zyban or Wellbutrin (Wellbutrin, Wellbutrin SR, and Wellbutrin XL), duration of treatment $(<1,1-3$, or $\geq 4$ years), gender (male or female), highest level of education (less than high school, high school graduate, some college/college graduate, or higher), and receipt of the Medication Guide (received or not received).

\section{Results}

\subsection{Participant Population}

In total, 50,985 survey invitations were distributed and 1017 $(2.0 \%)$ potential participants responded to invitations. A breakdown of participant recruitment via each of the three recruitment channels is provided in Table 1. Of the 1017 respondents, 280 self-identified as Wellbutrin users, and 43 as Zyban users. Overall, 144 (14.2\%) respondents were eligible to participate in the survey, $820(80.6 \%)$ were ineligible, and 53 (5.2\%) discontinued the survey before completing all eligibility screening questions (Fig. 1). The number of respondents to fail each eligibility criterion is shown in Table 2. A total of $142(14.0 \%)$ respondents completed the survey and were included in this study; demographic characteristics are summarized in Table 3 .

\subsection{Primary Outcome}

Correct answers were given by $\geq 80 \%$ of participants to 13 out of 16 individual questions about the neuropsychiatric risks associated with branded bupropion hydrochloride products. The proportion of participants who correctly responded to each question regarding neuropsychiatric risks is shown in Fig. 2. Results showed that $84.5 \%$ of participants were aware that antidepressant medicines may increase suicidal thoughts in the first few months of treatment. Notably, $>90 \%$ of participants correctly identified all listed ways to watch for and prevent suicidal thoughts or actions. In contrast, only $68.3 \%$ of the respondents understood that quitting smoking can lead to worsening of existing mental health problems, such as depression. Additionally, whilst $\geq 80 \%$ of patients
Table 1 Summary of survey administration for each recruitment channe
Fig. 1 Flow diagram of survey administration. ${ }^{\text {a Respondents }}$ who discontinued the survey before completing all eligibility questions were classified as respondents with undetermined eligibility

\begin{tabular}{llll}
\hline Parameter, $n(\%)$ & Online web panel & Pharmacy network & HCP referral \\
\hline Number of invitations distributed & 45,000 & 1875 & 4110 \\
All respondents & $941(2.1)$ & $48(2.6)$ & $28(0.7)$ \\
Eligible respondents & $133(14.1)$ & $1(2.1)$ & $10(35.7)$ \\
$\quad$ Complete surveys & $131(13.9)$ & $1(2.1)$ & $10(35.7)$ \\
$\quad$ Incomplete surveys & $2(0.2)$ & 0 & 0 \\
Ineligible respondents & $757(80.4)$ & $46(95.8)$ & $17(60.7)$ \\
Respondents with undetermined eligibility & $51(5.4)$ & $1(2.1)$ & $1(3.6)$ \\
\hline
\end{tabular}

$H C P$ healthcare provider

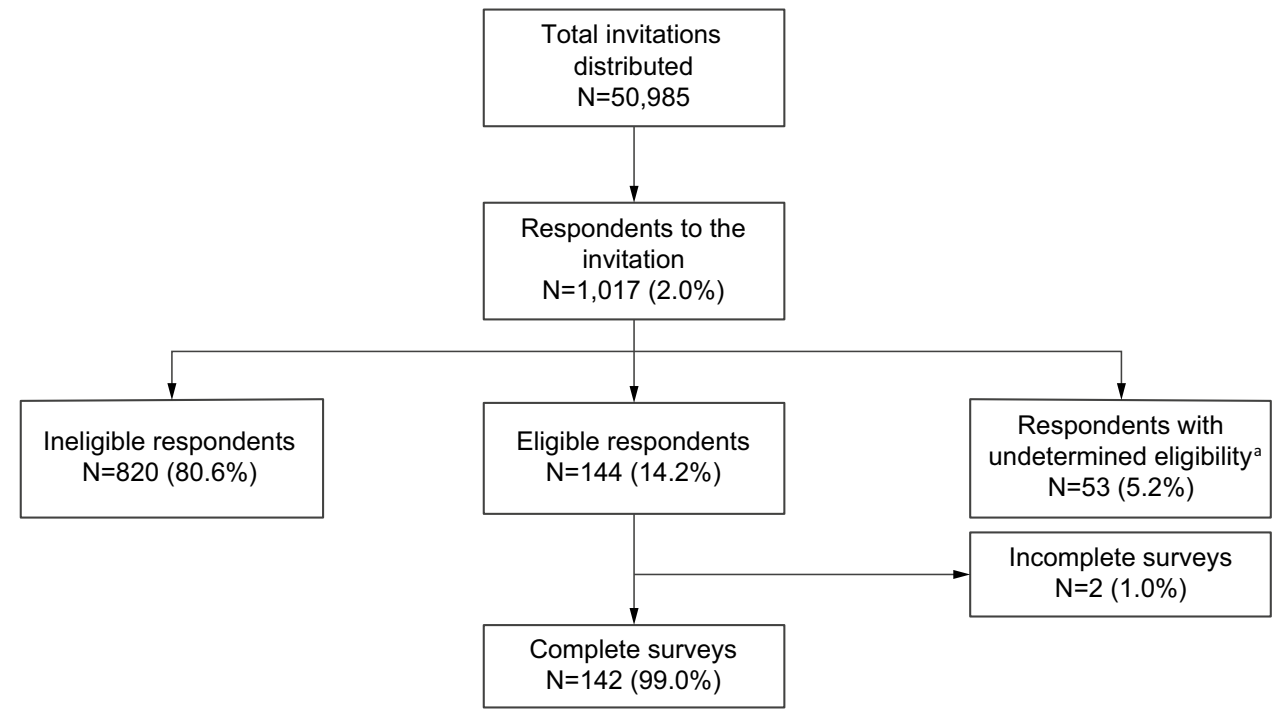


Table 2 Summary of eligibility criterion failure
Eligibility criterion failed

Ineligible respondents $(N=820), n(\%)$

Respondent did not agree to take part in the survey

$3(0.4)$

Respondent under 18 years of age

0

Respondent not currently taking prescription medication

187 (22.8)

Respondent not currently taking Wellbutrin, Wellbutrin SR, Wellbutrin XL or Zyban 436 (53.2)

Respondent taking Wellbutrin/Zyban manufactured by Teva, Watson or Mylan 71 (8.7)

Respondent last filled a prescription for Wellbutrin/Zyban more than 6 months ago 10 (1.2)

Respondent not taking Wellbutrin/Zyban for smoking cessation 112 (13.7)

Respondent previously participated in another survey for Wellbutrin/Zyban $1(0.1)$
Table 3 Summary of demographic characteristics (Completed Survey population)

\begin{tabular}{|c|c|c|c|}
\hline \multirow[t]{2}{*}{ Characteristics } & Zyban $(n=29)$ & Wellbutrin $(n=113)$ & Total $(N=142)$ \\
\hline & \multicolumn{3}{|c|}{ Number of participants (\%) } \\
\hline \multicolumn{4}{|l|}{ Gender (Question S9) } \\
\hline Male & $19(65.5)$ & $63(55.8)$ & $82(57.7)$ \\
\hline Female & $10(34.5)$ & $50(44.2)$ & $60(42.3)$ \\
\hline \multicolumn{4}{|l|}{ Age, years (Question S00) } \\
\hline $18-35$ & $7(24.1)$ & $33(29.2)$ & $40(28.2)$ \\
\hline $36-50$ & $8(27.6)$ & $45(39.8)$ & $53(37.3)$ \\
\hline $51-65$ & $14(48.3)$ & $33(29.2)$ & $47(33.1)$ \\
\hline 66-79 & 0 & $2(1.8)$ & $2(1.4)$ \\
\hline 80 or older & 0 & 0 & 0 \\
\hline \multicolumn{4}{|c|}{ For what medical reason are you taking Wellbutrin/Zyban? Select all that apply (Question S7) } \\
\hline Depression & $3(10.3)$ & $42(37.2)$ & $45(31.7)$ \\
\hline Smoking & $29(100.0)$ & $113(100.0)$ & $142(100.0)$ \\
\hline Other & 0 & $2(1.8)$ & $2(1.4)$ \\
\hline \multicolumn{4}{|c|}{ When did you first start taking Wellbutrin/Zyban? (Question 7) } \\
\hline$<1$ year ago & 17 (58.6) & 47 (41.6) & $64(45.1)$ \\
\hline $1-3$ years ago & $11(37.9)$ & $57(50.4)$ & $68(47.9)$ \\
\hline$>4$ years ago & $1(3.4)$ & $7(6.2)$ & $8(5.6)$ \\
\hline Can't recall & 0 & $2(1.8)$ & $2(1.4)$ \\
\hline \multicolumn{4}{|c|}{ What is the highest level of education you have completed? (Question 14) } \\
\hline Less than high school graduate & 0 & $2(1.8)$ & $2(1.4)$ \\
\hline High school graduate & $4(13.8)$ & $15(13.3)$ & $19(13.4)$ \\
\hline $\begin{array}{l}\text { Some college, professional or technical train- } \\
\text { ing/licensure }\end{array}$ & $10(34.5)$ & $40(35.4)$ & $50(35.2)$ \\
\hline College graduate or higher & $15(51.7)$ & $56(49.6)$ & $71(50.0)$ \\
\hline \multicolumn{4}{|c|}{ Geographic distribution (based on residence in the US) ${ }^{\mathrm{a}}$} \\
\hline Northeast & $10(34.5)$ & $23(20.4)$ & $33(23.2)$ \\
\hline Midwest & $3(10.3)$ & $22(19.5)$ & 25 (17.6) \\
\hline South & $7(24.1)$ & $48(42.5)$ & $55(38.7)$ \\
\hline West & $9(31.0)$ & $19(16.8)$ & 28 (19.7) \\
\hline Other & 0 & 0 & 0 \\
\hline Did not answer & 0 & $1(0.9)$ & $1(0.7)$ \\
\hline \multicolumn{4}{|c|}{ How do you normally receive your Wellbutrin/Zyban? (Question 13) } \\
\hline By mail & 0 & $3(2.7)$ & $3(2.1)$ \\
\hline At the pharmacy & $28(96.6)$ & $109(96.5)$ & $137(96.5)$ \\
\hline At the clinic & $1(3.4)$ & $1(0.9)$ & $2(1.4)$ \\
\hline
\end{tabular}

${ }^{a}$ US Census Bureau, last revised Friday, 27 July 2001 12:59:43 EDT, Geography Division. Northeast includes Connecticut, Massachusetts, Maine, New Hampshire, New Jersey, New York, Pennsylvania, Rhode Island, and Vermont. Midwest includes Iowa, Illinois, Indiana, Kansas, Michigan, Minnesota, Missouri, North Dakota, Nebraska, Ohio, South Dakota, and Wisconsin. South includes Alabama, Arkansas, District of Columbia, Delaware, Florida, Georgia, Kentucky, Louisiana, Maryland, Mississippi, North Carolina, Oklahoma, South Carolina, Tennessee, Texas, Virginia, and West Virginia. West includes Alaska, Arizona, California, Colorado, Hawaii, Idaho, Montana, New Mexico, Nevada, Oregon, Utah, Washington, and Wyoming. Other includes Puerto Rico 
Fig. 2 Proportion of participants who responded correctly to questions regarding neuropsychiatric risks associated with the use of branded bupropion hydrochloride products for smoking cessation (Completed Survey population). Different colors represent different numbered questions within the survey. $H C P$ healthcare provider. ${ }^{\text {aQ }}$ uestions were simplified for inclusion in the figure. Full questions are available in the Online Supplementary Materials

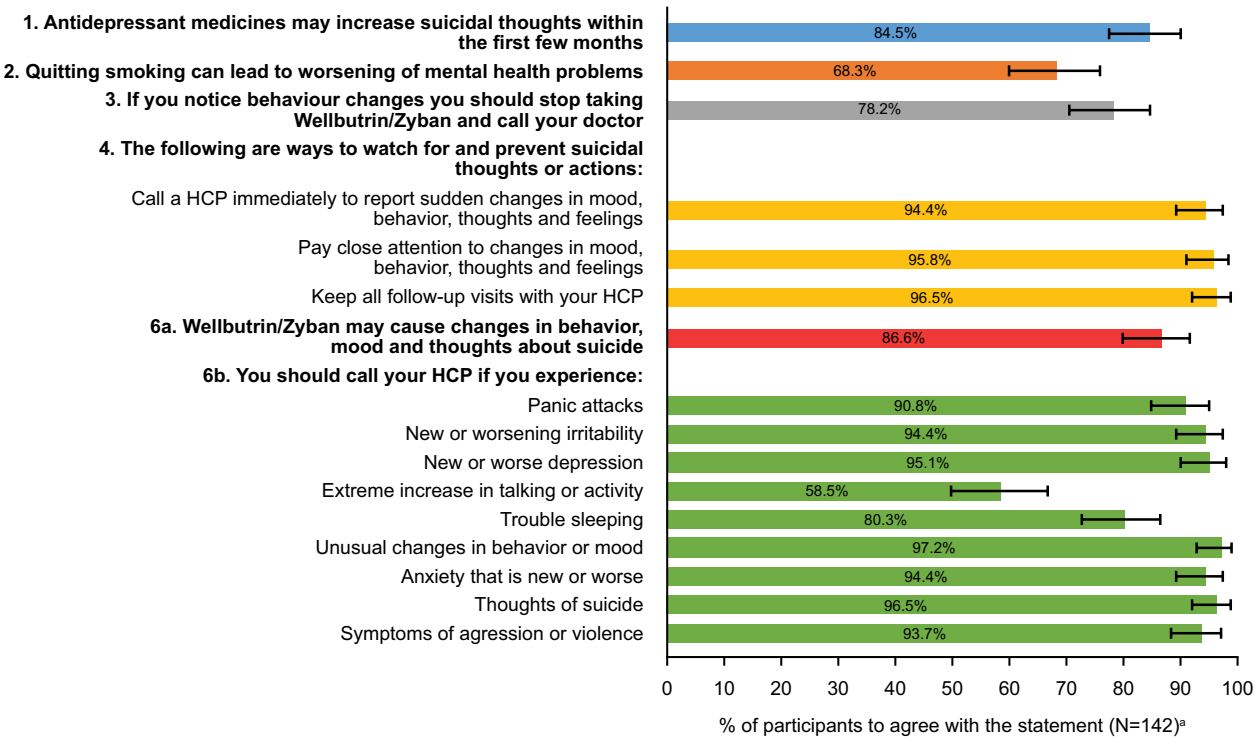

correctly identified most neuropsychiatric symptoms that should prompt them to call their doctor, only $58.5 \%$ considered an extreme increase in talking or activity to be among those symptoms.

\subsection{Other Outcomes}

Participants' knowledge of other risks associated with the use of branded bupropion hydrochloride products was also assessed. Results are summarized in Table 4. Overall, participants' knowledge of other risks was lower than their knowledge of neuropsychiatric risks. Approximately 50\% of participants correctly identified severe allergic reactions, seizures, and high blood pressure as other risks associated with the use of branded bupropion hydrochloride products.

Participants were also asked questions regarding receipt and reading of the Medication Guide. A total of $73.9 \%$ of participants (105/142) recalled receiving the Medication Guide when they last filled their prescription for a branded bupropion hydrochloride product (Fig. 3), of whom 57.1\% (60/105) reported that they had read the Medication Guide at that time. Amongst the participants who did not or could not recall reading the Medication Guide the last time they filled their prescription $(n=82), 69.5 \%(57 / 82)$ reported that they had read the Medication Guide at any time in the past (Fig. 3). In total, $76.1 \%$ of all survey respondents (108/142) reported that they had read the Medication Guide at any time in the past, with $18.5 \%(20 / 108)$ having read it less than a month ago, 51.9\% (56/108) having read it 1-6 months ago, $21.3 \%$ (23/108) having read it 7-12 months ago, and 8.3\% (9/108) having read it more than a year ago (data not shown).

Of the 108 participants who had read the Medication Guide in the past, $82.4 \%(89 / 108)$ reported that they read it thoroughly from beginning to end the first time they read it, and $17.6 \%$ (19/108) reported that they read it thoroughly the most recent time they read it (Fig. 4). Approximately half of the participants $(53 / 108 ; 49.1 \%)$ reported that they only read the parts that pertained to them the first time they read the Medication Guide, and half $(55 / 108 ; 50.9 \%)$ did so the most recent time they read it (Fig. 4). Most participants (80/108; 74.1\%) who reported ever reading the Medication Guide also reported skimming through it quickly the most recent time they read it (Fig. 4).

\subsection{Safety Outcomes}

Fourteen reports of potential adverse events were mentioned spontaneously by participants in free-text fields of the questionnaire or whilst talking to the CCA (data not shown). All reports of adverse events were forwarded to GSK in accordance with the Safety Event Reporting Procedure.

\subsection{Subgroup Analyses}

Analysis by subgroups, including treatment formulation, duration of treatment, gender, education, or receipt of the Medication Guide, produced results that were mostly consistent with the main results, with few notable differences (data tables not shown). When asked if quitting smoking could lead to worsening of existing mental health problems, a higher proportion of participants who had been taking branded bupropion hydrochloride for 1-3 years correctly responded (73.5\%), compared with participants who had been taking branded bupropion hydrochloride for $<1$ year (62.5\%). Additionally, a higher proportion of female $(65.0 \%)$ than male $(53.7 \%)$ participants responded that they should 
Table 4 Proportion of participants who responded correctly to questions regarding additional risks associated with the use of Wellbutrin or Zyban (Completed Survey population)

Question/response Participants $(N=142)$ $n(\%),[95 \% \mathrm{CI}]^{\mathrm{a}}$

Question 1: Please indicate whether each of the following statements are true or false

Antidepressant medicines may cause increased infections

False $^{\mathrm{b}}$

$48(33.8),[26.1-42.2]$

Question 5: Do people taking Wellbutrin/Zyban have a higher chance of experiencing each of the following risks?

Stomach ulcers

$\mathrm{No}^{\mathrm{b}}$

41 (28.9), [21.6-37.1]

Kidney stones

$\mathrm{No}^{\mathrm{b}}$

52 (36.6), [28.7-45.1]

Severe allergic reactions

$\mathrm{Yes}^{\mathrm{b}}$

70 (49.3), [40.8-57.8]

Seizures

Yes $^{\text {b }}$

66 (46.5), [38.1-55.0]

High blood pressure

Yes $^{\text {b }}$

Question 6a: Which of the following could be possible side effects of Wellbutrin/Zyban?

Wellbutrin/Zyban may cause ear pain

$\mathrm{No}^{\mathrm{b}}$

Wellbutrin/Zyban may cause indigestion

$\mathrm{No}^{\mathrm{b}}$

34 (23.9), [17.2-31.8]

Wellbutrin/Zyban may increase the risk of seizures in people with certain medical conditions and in people who take certain medicines

Yes $^{\text {b }}$

94 (66.2), [57.8-73.9]

Question 6b: Which of the following symptoms should prompt you to call the doctor, especially if they are new, worse, or worry you?

Indigestion

$\mathrm{No}^{\mathrm{b}}$

49 (34.5), [26.7-42.9]

Sleeping more than usual

$\mathrm{No}^{\mathrm{b}}$

27 (19.0), [12.9-26.4]

Seizures

$\mathrm{Yes}^{\mathrm{b}}$

129 (90.8), [84.9-95.0]

${ }^{\mathrm{a}} 95 \%$ exact two-sided confidence intervals are calculated using the Clopper-Pearson method

${ }^{\mathrm{b}}$ Correct response

call their doctor if they experience an extreme increase in talking or activity. No substantial differences were observed when participants were stratified by treatment formulation.

\section{Discussion}

Overall, participants in this Year 7 REMS survey were knowledgeable about the neuropsychiatric risks associated with branded bupropion hydrochloride products when used for smoking cessation, as described in the Medication Guides. Correct responses were given by $\geq 80 \%$ of participants to 13 out of 16 questions regarding neuropsychiatric risks. Although this result did not meet the objective of correct responses by $\geq 80 \%$ of participants to all questions on neuropsychiatric risks, participants showed a good understanding of ways to watch for and prevent suicidal thoughts and actions, and symptoms that should prompt participants to stop taking their branded bupropion hydrochloride product and call a doctor. This threshold has been applied in previous surveys on other medicines and has been deemed to reflect a good understanding of risks [20, 21]. Receipt and reading of the Medication Guide was reported to be reasonably high, with nearly three-quarters of participants reporting that they received the Medication Guide last time they filled their prescription, and a total of $82.4 \%$ of participants reporting that they had ever read the Medication Guide. Subgroup analyses showed no difference in knowledge of 
Fig. 3 Summary of participant responses to questions ${ }^{\mathrm{a}}$ regarding reading of the Medication Guide (Completed Survey population). ${ }^{\mathrm{a}} \mathrm{Questions}$ were simplified for inclusion in the figure. Full questions are available in the Online Supplementary Materials. 'Participants who previously answered "No" or "Can't recall" to Question 8 were not asked this question. cParticipants who previously answered "Yes" to Question 9 were not asked this question. ${ }^{\mathrm{d}}$ Participants who previously answered "No" or "Can't recall" to Question 8 or Question 9 were not asked this question
Question 8: Did you receive the Medication Guide last time you filled your prescription for Wellbutrin/Zyban?

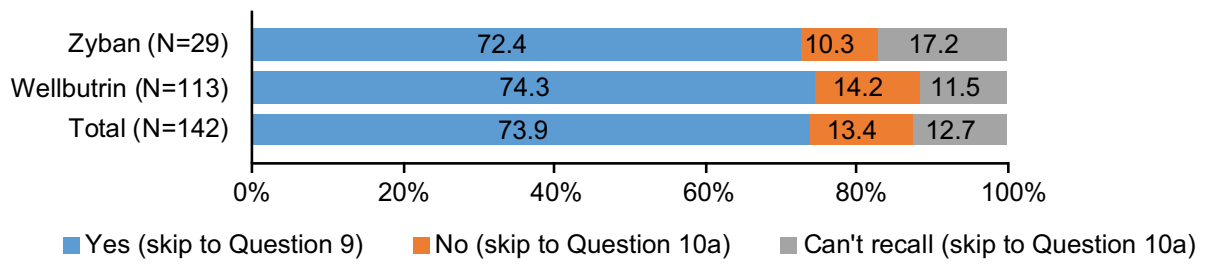

Question 9b: Did you read the Medication Guide when you last filled in your prescription?

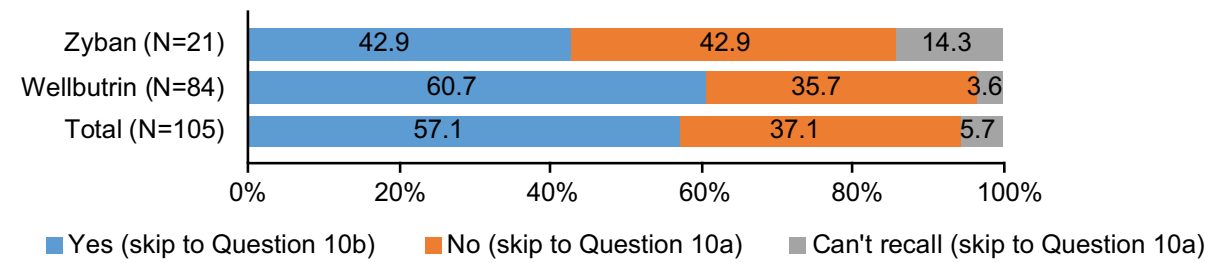

Question $10 a^{c}$ : Have you ever read the Medication Guide?

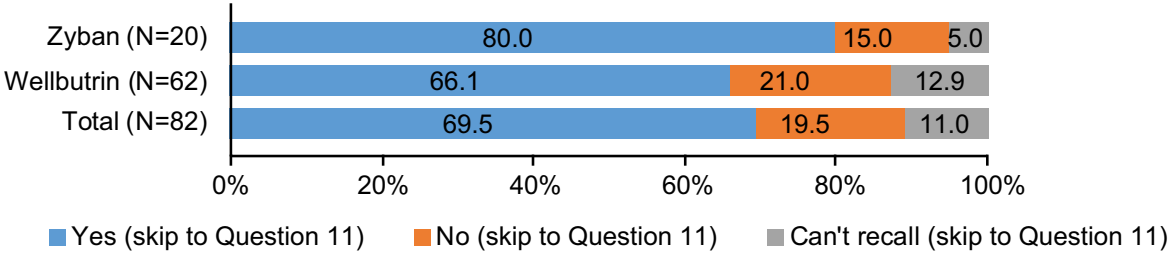

Question 10bd: Did you ever read the Medication Guide before you received the last prescription?

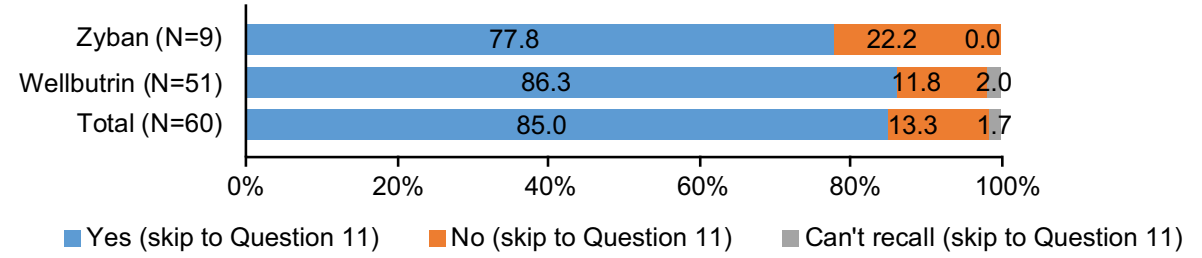

neuropsychiatric risks with treatment formulation, duration of treatment, gender, education level, or receipt of the Medication Guide.

There were only three questions regarding neuropsychiatric risks that were not correctly answered by $\geq 80 \%$ of participants. First, $68.3 \%$ of patients correctly responded that quitting smoking could lead to a worsening of existing mental health problems. This finding demonstrates a lack of participant understanding of the risks associated with smoking cessation itself, and highlights the need for physicians to warn patients with mental health problems of the increase in symptoms they may experience when trying to quit smoking. Secondly, $58.5 \%$ of patients identified an extreme increase in talking or activity among the symptoms that should prompt them to stop taking their branded bupropion product and call their doctor. Finally, $78.2 \%$ of participants correctly responded that if they or a family member notice changes in their behavior, they should stop taking their branded bupropion product and call their doctor.
Fewer participants correctly responded to questions regarding other risks associated with the use of branded bupropion hydrochloride products. Approximately 50\% of participants correctly identified the other risks associated with branded bupropion products. This lower level of understanding of other risks compared with neuropsychiatric risks is consistent with the results of previous studies reporting on REMS assessments for varenicline use for smoking cessation $[23,24]$. This may reflect the fact that the Medication Guides place more importance on the risk of neuropsychiatric risks versus other risks [23-25]. Alternatively, it is important to note that participants may have received information from other sources, such as warnings on the box or counselling by healthcare professionals, and these too may have focused on educating patients on neuropsychiatric risks over other risks [23-25].

Overall, the results of this study have demonstrated that most patients have an acceptable level of understanding of the neuropsychiatric risks associated with the use of branded 
Fig. 4 Summary of how thoroughly participants reported having read the Medication Guide the first time and the most recent time they read it (Completed Survey population $\left.{ }^{\mathrm{a}}\right)$. ${ }^{\mathrm{a}}$ Participants who previously answered "No" or "Can't recall" to Question 10a or $10 \mathrm{~b}$ were not asked this question
I read it thoroughly from beginning to end

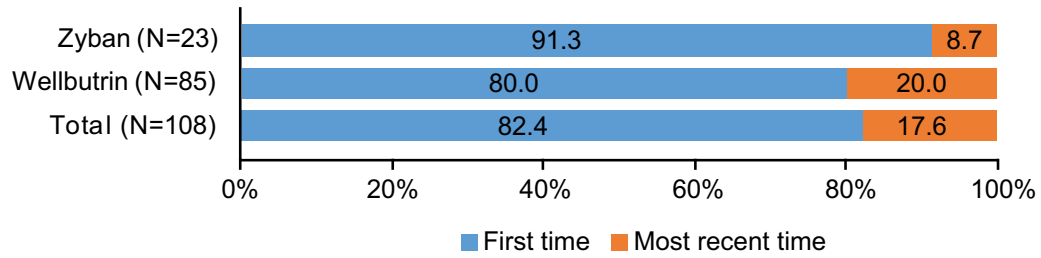

I read the parts that pertain to me

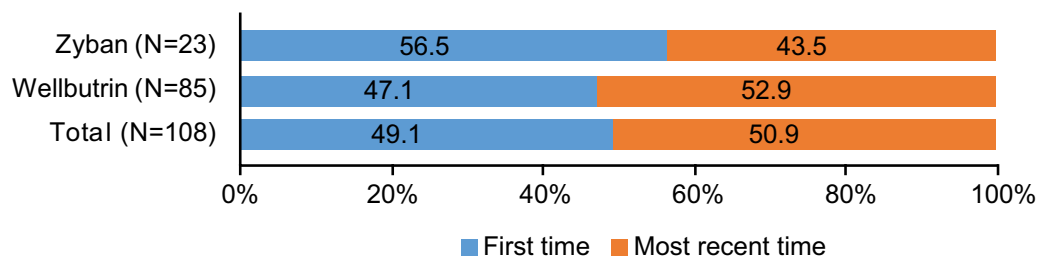

I skimmed through it quickly

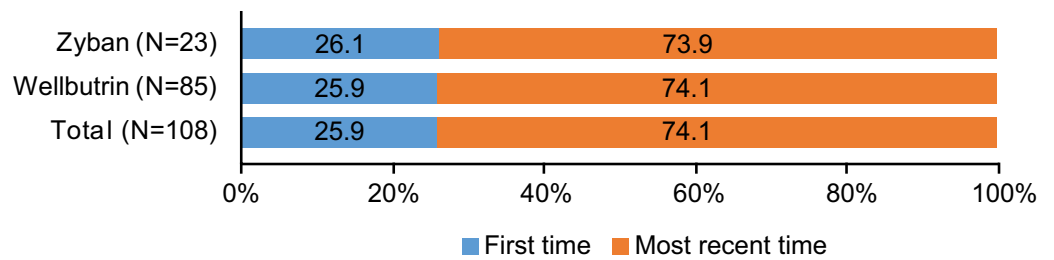

bupropion hydrochloride products. This indicates that the current methods employed to communicate bupropion hydrochloride risks are effective; however, as participants may have obtained information from various sources, it remains challenging to isolate and quantify the impact of the Medication Guide on participants' understanding of neuropsychiatric risks [25]. Through also including participants taking Wellbutrin for smoking cessation, this study has provided additional insight into understanding of neuropsychiatric risks among patients taking branded bupropion hydrochloride products, and has demonstrated that understanding is uniformly high irrespective of treatment formulation.

There were a number of limitations inherent to the design of this study. As participants responded to survey invitations voluntarily, the sample size was limited by the survey response rate, which in this case was low (2.0\%). This low response rate may have introduced bias as the survey population may not have been fully representative of all patients prescribed branded bupropion hydrochloride products for smoking cessation. It was not possible to determine the extent of this inherent limitation because no data were available on potential differences between responders and non-responders. However, efforts were made to recruit a diverse range of patients through the use of three different recruitment channels (online web panel, HCP referral, and through a pharmacy network), which covered many geographic regions and made the survey accessible to participants who may not be computer-literate. Additionally, incentives associated with increased response rates, including a monetary incentive (\$25.00 gift card for eligible participants who completed the survey) and assurance of confidentiality, were provided [26]. Evidence suggests that additional efforts, such as pre-notification of the survey, reminders, or more personalized survey questionnaires, letters, and emails, may have been effective at increasing response rate [26]. Recruitment of some participants through HCP referral may have introduced selection bias, as HCPs may have been more likely to invite patients thought to have a greater knowledge of the associated risks. Analysis of patient responses by recruitment method could have made an interesting subgroup analysis to assess any potential selection bias introduced through different recruitment channels. However, only one patient was recruited by the pharmacy network, and ten through HCP referral (Table 1). As such, there were insufficient numbers of patients to warrant a subgroup analysis by recruitment method, and it was therefore not possible to assess the level of selection bias introduced through HCP referral. Response bias, where participants are able to predict the correct or desired response, is also inherent to surveys of this nature; however, this limitation was addressed by the inclusion of multiple choice options to minimize participants' ability to detect correct responses. Also, given the online and telephone-based survey administration, it was not possible to ascertain whether participants had the Medication Guide present at the time the survey was completed. Finally, the number of Zyban users included in this study was relatively small. However, given that the same potential risks exist across all bupropion users, especially those using 
the products off label, the results are relevant to patients using Zyban and Wellbutrin products for smoking cessation.

\section{Conclusion}

This Year 7 REMS survey has found patients to have a good understanding of the neuropsychiatric risks associated with branded bupropion hydrochloride products used for smoking cessation, indicating that the Medication Guide may be an effective tool for informing patients of the potential risks.

Acknowledgements Trademarks for Zyban, Wellbutrin, and Wellbutrin SR are owned by the GSK group of companies. The trademark for Wellbutrin XL is owned by Valeant and licensed to the GSK group of companies. Editorial support (in the form of writing assistance, including development of the initial draft from the clinical study report, assembling tables and figures, collating authors' comments, grammatical editing, and referencing) was provided by Natasha Dean, MSc, and Alex Lowe, PhD, at Fishawack Indicia Ltd, UK, and was funded by GSK.

Authors' contributions Monika Stender, John Ascher, Christina Winter, Beta Win, and Annette Stemhagen contributed to concept and design of the study. Annette Stemhagen was involved in acquisition of data. Monika Stender, John Ascher, Christina Winter, and Annette Stemhagen were involved in data analysis and interpretation. All authors were involved in preparation and review of the manuscript and approved the final version to be submitted.

\section{Compliance with ethical standards}

Funding This study was funded by GlaxoSmithKline (GSK ID 205913).

Conflicts of interest John Ascher, Beta Win, and Christina Winter are all employees of GSK and all hold stocks/shares in GSK. Monika Stender was an employee at GSK at the time of the study and holds stocks/shares in GSK. Annette Stemhagen is an employee of $U B C$.

Informed consent All participants provided written consent to take part in the survey.

Open Access This article is distributed under the terms of the Creative Commons Attribution-NonCommercial 4.0 International License (http://creativecommons.org/licenses/by-nc/4.0/), which permits any noncommercial use, distribution, and reproduction in any medium, provided you give appropriate credit to the original author(s) and the source, provide a link to the Creative Commons license, and indicate if changes were made.

\section{References}

1. GlaxoSmithKline. ZYBAN (bupropion hydrochloride) Sustained-Release Tablets; prescribing information. 2014. www. gsksource.com/pharma/content/gsk/source/us/en/brands/zyban .html Accessed 13 Oct 2017.

2. GlaxoSmithKline. WELLBUTRIN (bupropion hydrochloride tablets) prescribing information. 2009. https://www.accessdata .fda.gov/drugsatfda_docs/label/2009/018644s039s040.pdf Accessed 13 Oct 2017.

3. GlaxoSmithKline. WELLBUTRIN SR (bupropion hydrochloride sustained-release tablets) prescribing information. 2010. https://www.accessdata.fda.gov/drugsatfda_docs/label /2011/020358s039s0491bl.pdf Accessed 13 Oct 2017.

4. GlaxoSmithKline. WELLBUTRIN XR (bupropion hydrochloride extended-release tablets) prescribing information. 2009. http://www.accessdata.fda.gov/drugsatfda_docs/label /2009/021515s023s024lbl.pdf Accessed 13 Oct 2017.

5. Cahill K, Stevens S, Perera R, Lancaster T. Pharmacological interventions for smoking cessation: an overview and network meta-analysis. Cochrane Database Syst Rev. 2013;5:CD009329. https://doi.org/10.1002/14651858.cd009329.pub2.

6. Hughes JR, Stead LF, Hartmann-Boyce J, Cahill K, Lancaster T. Antidepressants for smoking cessation. Cochrane Database Syst Rev. 2014;1:CD000031. https://doi.org/10.1002/14651858. cd000031.pub4.

7. Anthenelli RM, Benowitz NL, West R, St Aubin L, McRae $T$, Lawrence D, et al. Neuropsychiatric safety and efficacy of varenicline, bupropion, and nicotine patch in smokers with and without psychiatric disorders (EAGLES): a doubleblind, randomised, placebo-controlled clinical trial. Lancet. 2016;387(10037):2507-20. https://doi.org/10.1016/s0140 $-6736(16) 30272-0$.

8. Thomas KH, Martin RM, Davies NM, Metcalfe C, Windmeijer F, Gunnell D. Smoking cessation treatment and risk of depression, suicide, and self harm in the Clinical Practice Research Datalink: prospective cohort study. BMJ. 2013;347:f5704. https ://doi.org/10.1136/bmj.f5704.

9. Beyens MN, Guy C, Mounier G, Laporte S, Ollagnier M. Serious adverse reactions of bupropion for smoking cessation: analysis of the French Pharmacovigilance Database from 2001 to 2004. Drug Saf. 2008;31(11):1017-26.

10. Moore TJ, Furberg CD, Glenmullen J, Maltsberger JT, Singh $\mathrm{S}$. Suicidal behavior and depression in smoking cessation treatments. PLoS One. 2011;6(11):e27016. https://doi.org/10.1371/ journal.pone.0027016.

11. Soyka M. Neuropsychiatric adverse events of bupropion treatment: a brief update. Int J Psychiatry Clin Pract. 2004;8(4):2514. https://doi.org/10.1080/13651500410005630.

12. FDA. A Brief Overview of Risk Evaluation \& Mitigation Strategies (REMS). https://www.fda.gov/AboutFDA/Transparency/ Basics/ucm325201.htm. Accessed 8 Nov 2017.

13. Knox C, Hampp C, Willy M, Winterstein AG, Dal Pan G. Patient understanding of drug risks: an evaluation of medication guide assessments. Pharmacoepidemiol Drug Saf. 2015;24(5):518-25. https://doi.org/10.1002/pds.3762.

14. GlaxoSmithKline. NDA 20-711 ZYBAN ${ }^{\circledR}$ (bupropion hydrochloride) Sustained-Release Tablets. Risk Evaluation and Mitigation Strategy (REMS). Food \& Drug Administration. 2009. https://www.accessdata.fda.gov/drugsatfda_docs/label /2010/020711s034REMSZyban.pdf. Accessed 3 Nov 2017.

15. Rappaport B. Food and Drug Administration Supplement Approval. 2014. https://www.accessdata.fda.gov/drugsatfda _docs/appletter/2014/020711Orig1s0391tr.pdf. Accessed 3 Nov 2017.

16. GlaxoSmithKline. Medication Guide Zyban Sustained Release Tablets. 2009. https://www.accessdata.fda.gov/drugsatfda_docs/ label/2010/020711s034MedGuide.pdf. Accessed 20 Oct 2017.

17. GlaxoSmithKline. Medication Guide Wellbutrin XL. 2009. https ://www.accessdata.fda.gov/drugsatfda_docs/label/2010/02151 5s025MedGuide.pdf. Accessed 20 Oct 2017.

18. GlaxoSmithKline. Medication Guide Wellbutrin Tablets. 2009. https://www.accessdata.fda.gov/drugsatfda_docs/label /2010/018644s041MedGuide.pdf. Accessed 20 Oct 2017. 
19. GlaxoSmithKline. Medication Guide Wellbutrin SustainedRelease Tablets. 2013. https://www.fda.gov/downloads/Drugs/ DrugSafety/ucm089826.pdf. Accessed 20 Oct 2017.

20. Ishihara L, Beck M, Travis S, Akintayo O, Brickel N. Physician and Pharmacist Understanding of the Risk of Urinary Retention with Retigabine (Ezogabine): a REMS Assessment Survey. Drugs Real World Outcomes. 2015;2(4):335-44. https ://doi.org/10.1007/s40801-015-0042-5.

21. DiSantostefano RL, Beck M, Yeakey AM, Raphiou I, Stempel DA. Patient comprehension of medication guides for asthma and chronic obstructive pulmonary disease medications. Therapeutic Innov Regul Sci. 2014;48(5):574-82. https://doi. org/10.1177/2168479014524407.

22. Clopper CJ, Pearson ES. The use of confidence or fiducial limits illustrated in the case of the binomial. Biometrika. 1934;26(4):404-13. https://doi.org/10.2307/2331986.

23. Amend KL, Younus M, Petronis KR, Mo J, Seeger JD, Gately $\mathrm{R}$, et al. Assessment of risk evaluation and mitigation strategies
(REMS) for varenicline (Chantix): a multistage patient survey. Pharmacoepidemiol Drug Saf. 2018;27(3):253-62. https://doi. org/10.1002/pds.4373.

24. Enger C, Younus M, Petronis KR, Mo J, Gately R, Seeger JD. The effectiveness of varenicline medication guide for conveying safety information to patients: a REMS assessment survey. Pharmacoepidemiol Drug Saf. 2013;22(7):705-15. https://doi. org/10.1002/pds.3400.

25. Dal Pan GJ. Commentary on "The effectiveness of varenicline medication guide for conveying safety information to patients: a REMS assessment survey" by Enger et al. Pharmacoepidemiol Drug Saf. 2013;22(7):716-8. https://doi.org/10.1002/pds.3450.

26. Edwards PJ, Roberts I, Clarke MJ, Diguiseppi C, Wentz R, Kwan I, et al. Methods to increase response to postal and electronic questionnaires. Cochrane Database Syst Rev. 2009;3:000008. https://doi.org/10.1002/14651858.mr000008.pub4. 